\title{
Relato de experiência: cuidados de enfermagem relacionados à epitelização de feridas
}

\author{
Camilla Alves de Souza, Gláucia Bohusch, Leticia Lourenço, Thamires Simão Marques
}

\begin{abstract}
Resumo
A atenção básica no município do Rio de Janeiro vem trazendo uma melhoria na assistência às pessoas com doenças crônicas não transmissíveis através de ações de promoção da saúde, vigilância em saúde, prevenção de doenças e assistência à população. A Diabetes mellitus, síndrome que leva ao metabolismo imperfeito de carboidratos, lipídios e proteínas detém destaque nas Unidades de Saúde da cidade. Isso por que, uma de suas complicações, a neuropatia diabética é o principal fator causal de ulcerações e amputações, que além dos gastos com recursos hospitalares, envolve psicológico do usuário. Objetivo do estudo é relatar a experiência dos cuidados de enfermagem na sala de curativos frente à úlcera em coto oriundo da amputação de metatarsos esquerdo. $\mathrm{O}$ estudo contribui para o ensino, na formação de profissionais de saúde, gerando uma reflexão sobre a implementação de ações para a realização sistemática de avaliação de feridas. Para a prática, contribui dando maior visibilidade às ações que proporcionam êxito no acompanhamento de feridas podendo, assim, fazer com que a equipe reconheça a importância de planejar de forma consciente ações e seus possíveis efeitos sobre aqueles que as vivenciam. Já para a pesquisa o estudo contribui gerando futuras investigações sobre a cicatrização de feridas em usuários portadores de diabetes. Relato de experiência de natureza qualitativa e caráter exploratório. Com o início do Programa de Residência de Enfermagem em Saúde da Família, a sistematização da avaliação de feridas e a realização de curativos semanalmente, foi possível proporcionar a cicatrização da ferida do usuário, idoso, que convivia com a ferida há oito anos após amputação de metatarsos. Pode-se concluir que o sucesso no manejo de feridas requer o planejamento da assistência, avaliação e tratamento elegendo o melhor tipo de cobertura para a realização de curativo. Sendo fundamental que o usuário receba orientações sobre sua patologia e sobre a realização de curativo em domicílio para que compreenda que é corresponsável pelo alcance dos resultados esperados durante o tratamento.
\end{abstract}

Descritores: Enfermagem; Saúde da Família; Pé Diabético. 